INVITED ARTICLE

\title{
Transfusion Triggers for Platelets and Other Blood Products
}

\author{
Sunil Karanth \\ Indian Journal of Critical Care Medicine (2019): 10.5005/jp-journals-10071-23250
}

\section{INTRODUCTION}

Transfusion of whole blood is not associated with any significant benefit, rather can be harmful. Significant advances have been made in transfusion medicine, facilitating the use of blood product or component therapy than use of whole blood (Fig. 1). In 2009, a report on Serious Hazards of Transfusion in the UK, estimated that a total of 3 million units of blood components were released. The requirement of the same in South-East Asia is much higher to the tune of 15 million units annually. The current recommendation is to use blood only in life-threatening situations, rather than to normalize abnormal numbers.

\section{Platelets}

Platelets are derived from the buffy coat of whole blood donations. A pooled platelet concentrate includes pooled buffy-coat derived platelets from four whole-blood donations suspended in platelet additive solution and plasma of one of the four donors. It contains 240000 platelets pooled from 4-6 donors. A Single donor platelet is derived from a single-donor by a process of apheresis. In view of the lesser number of donors and the theoretical advantage of involving a single-donor platelet (SDP) may be preferred over the use of platelets from multiple donors. A SDP, may contain at least 55000 platelets.

Some of the important characteristics of platelet transfusions include storage at $20-24$ degree Centigrade $\left({ }^{\circ} \mathrm{C}\right)$ with constant agitation for 5 days, the need to be transfused within 4 hours of collection, at a rate not less than 30 minutes. Based on the various indications and available guidelines, the following are the indications for transfusion of platelets: ${ }^{1,2}$

- Active bleeding in the presence of platelet defects.

- Platelet count of $<50000 / \mathrm{mm}^{3}$ in patients with active bleeding.

- In hemtatology patients having active bleeding associated with dengue, malaria, kalaazar and autoimmune platelet disorders

- In oncology patients:

- Patients with platelet counts $<20000 / \mathrm{mm}^{3}$, in the presence of risk factors.

- Patients with platelet counts $<10000 / \mathrm{mm}^{3}$ with no risk factors.

- In patients needing surgical or any other interventions:

- Platelet count $<50000 / \mathrm{mm}^{3}$, if there is minimal risk of bleeding

- Platelet $<100000 / \mathrm{mm}^{3}$, for any ophthalmic or central nervous system surgeries.

- Part of massive transfusion protocol as specific blood component therapy

- In severe uncontrolled bleeding, postcardiopulmonary by pass.

\section{Fresh Frozen Plasma}

Fresh Frozen Plasma (FFP) is the liquid part of the blood obtained after separation of the cellular part of the blood. The separated liquid part is immediately frozen. FFPs have a volume of 200-300
Department of Intensive Care Unit, Manipal Hospital, Bengaluru, Karnataka, India

Corresponding Author: Sunil Karanth, Department of Intensive Care Unit, Manipal Hospital, Bengaluru, Karnataka, India, e-mail: drsunilkaranth@gmail.com

How to cite this article: Karanth S. Transfusion Triggers for Platelets and Other Blood Products. Indian J Crit Care Med 2019;23(Suppl 3):S189-S190.

Source of support: Nil

Conflict of interest: None

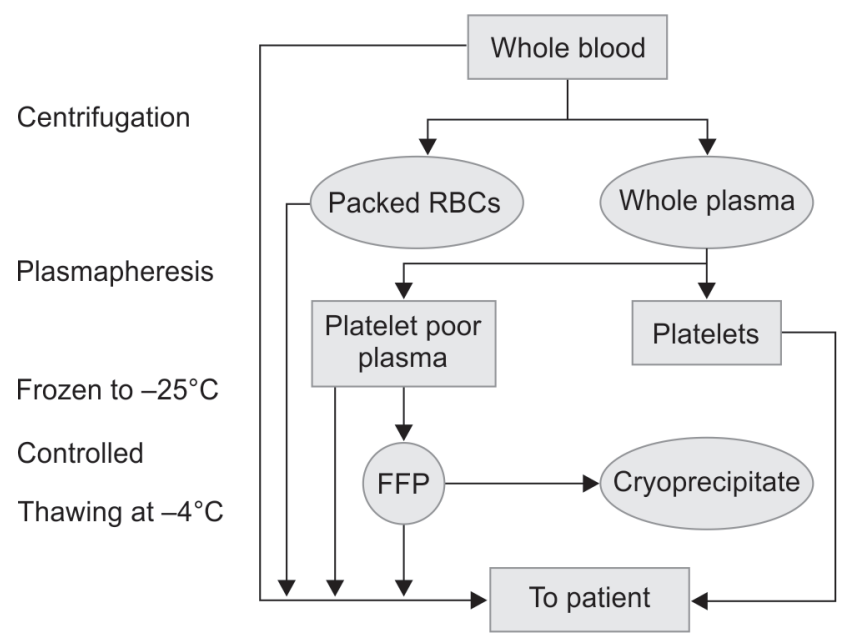

Fig. 1: Separation of whole blood into its components

$\mathrm{mL}$, frozen to a temperature of $-25^{\circ} \mathrm{C}$ within 6 hours, to ensure activity of the coagulation factors. FFPs can be stored for upto one year at a temperature of $-25^{\circ} \mathrm{C}$. However, prior to administration, FFPs would be needed to be thawed, and need to be used within 30 minutes of thawing. FFPs primarily contain stable clotting factors, albumin and Immunoglobulins. Generally, the dose of FFPs ranges $10-15 \mathrm{~mL} / \mathrm{kg}$. The target INR is 1.7 , prothrombin time (PT) $<1.5$ or a activated Prothrombin time (APTT) of less than twice the normal. Transfusions of FFPs are indicated in the following clinical situations: ${ }^{3}$

- Presence of laboratory proven coagulopathy with active bleeding. Laboratory proven includes PT $>1.5$, INR $>2$ and aPTT $>$ twice the normal limit.

- Emergency reversal of Warfarin effect, especially if there is need for an urgent surgery or when there is ongoing active bleeding.

- Dilutional coagulopathy-having a procedure or in the presence of active bleeding.

- Liver disease with coagulopathy in the presence of active bleeding or needing an intervention.

(0) The Author(s). 2019 Open Access This article is distributed under the terms of the Creative Commons Attribution 4.0 International License (https://creativecommons. org/licenses/by-nc/4.0/), which permits unrestricted use, distribution, and non-commercial reproduction in any medium, provided you give appropriate credit to the original author(s) and the source, provide a link to the Creative Commons license, and indicate if changes were made. The Creative Commons Public Domain Dedication waiver (http://creativecommons.org/publicdomain/zero/1.0/) applies to the data made available in this article, unless otherwise stated. 
- Prophylaxis in patients with coagulopathy undergoing surgery or other invasive procedures.

- Replacement of single factor deficiencies namely, factors $V$ and XI.

\section{Cryoprecipitate}

Cryoprecipitate is the fraction of the liquid part of the blood (plasma), which is undissolved following thawing of the plasma. Cryoprecipitate contains fibrinogen (150-300 mg/pack), factor VIII (80-100 IU/pack), von Willebrand factor and fibronectin. Similar to FFPs, cryoprecipitate packs can be stored at $-25^{\circ} \mathrm{C}$ for up to one year. The thawed product needs to be used within 6 hours of thawing. The indications for the transfusion of Cryoprecipitate include the following: ${ }^{4}$

- Fibrinogen levels $<100 \mathrm{mg} / \mathrm{dL}$ in patients with bleeding

- Massive transfusion

- Factor XIII deficiency

- Liver disease in the presence of active bleeding

- Disseminated intravascular coagulation (DIC)in the presence of active bleeding.

\section{Factor Concentrates}

Individual factor concentrates are available as replacement products for a few specific factors. However, high costs and limited availability have not made these products popular as a routine modality of therapy. In a community setting, specific factor concentrates are used in the management of hemophilia patients. Some of the clinical significant factor concentrates include:

- Recombinant or plasma-derived factor VIII: The use of this factor is recommended in the treatment of moderate to severe hemophilia A (factor VIII deficiency). In mild deficiency, it is usually not required, unless unresponsive to desmopressin.

- Recombinant or plasma-derived factor IX deficiency: It is recommended in the treatment of hemophilia B (factor IX deficiency)

- Activated prothrombin complex concentrates: It is used for bleeding episodes or prior to surgical procedures in patients with hemophilia $\mathrm{A}$ or $\mathrm{B}$, if individual components or factors are not available. They are also recommended in the presence of inhibitors to native coagulation factors.

- Prothrombin complex concentrates: It comes as four-factor concentrates containing factors II, VII, IX and X, with protein $S, C$ and heparin. It is used for urgent reversal of warfarin in a situation of a life-threatening bleeding or in the setting of deficiencies of other vitamin-K dependent factors, where obtaining specific factors may be practically difficult. ${ }^{5}$

\section{References}

1. Kaufman RM, Benjamin D, Gernsheimer T, Kleinman S, Tinmouth AT, Kelley EC, et al. Platelet transfusion a Clinical practice guideline from AAB. Ann Intern Med. 2015;162:205-213.

2. Slichter SJ, Kaufman RM, Assmann SF, McCullough J, Triulzi DJ, Strauss $\mathrm{RG}$, et al. Dose of prophylactic platelet transfusions and prevention of hemorrhage. N Engl J Med 2010;362:600-613.

3. Clinical Practice Guidelines on the Use of Blood Components. Appropriate Use of Fresh Frozen Plasma and Cryoprecipitate. NHMRC and Australian Society of Blood Transfusion; August, 2010.

4. Callum JL, Karkouti K, Lin Y. Cryoprecipitate: the current state of knowledge. Transfus Med Rev 2009;23:177-188.

5. Gill R, Herbertson M, Vuylsteke A, Olsen PS, von Heymann C, Mythen $M$, et al. Safety and efficacy of recombinant activated factor VII: a randomized placebo-controlled trial in the setting of bleeding after cardiac surgery. Circulation 2009;120:21-27. 